\title{
BILLBOARD ADVERTISING MODELING BY USING NETWORK COUNT LOCATION PROBLEM
}

\author{
Hamid Reza Lashgarian Azad ${ }^{1}$, Nader Shetab Boushehri ${ }^{2}$ \\ ${ }^{1,2}$ Industrial Engineering Department, Isfahan University of Technology, Isfahan, Iran
}

Received 14 December 2013; accepted 6 February 2014

\begin{abstract}
Many applications in engineering and science rely on the optimization of computationally cost functions. A successful approach in such states is to couple an evolutionary algorithm with a mathematical model which replaces the cost function. By considering of importance of advertising in the business declaration, especially billboard advertising, in this paper we have formulated billboard selection decision making, by using network count location approach which determine informative links in a network, to optimize cost of advertising and billboard visiting. Then, opposition based colonial competitive algorithm, which originally inspired by imperialistic competition, is used to solve mathematical model. Also, we implement proposed model on Sioux Falls city network.
\end{abstract}

Keywords: optimization, billboard advertising, opposition based colonial competitive algorithm, network count location problem.

\section{Introduction}

A basic description of advertising that Merriam-Webster Dictionary (2011) presented is to "The action of calling something to the attention of the public especially by paid announcements". A more descriptive definition presented by Entrepreneur (2011) is "To call the public's attention to your business, usually for the purpose of selling products or services, through the use of various forms of media, such as print or broadcast notices". Advertising presents a direct line of statement to existing and potential customers with regards to a product or service. Advertising has its origin in Europe, although some of its forms, such as radio and television commercials, as well as advertising on the Internet, for example, are uniquely American. In the study of O'Barr (2010), a main factor in advertising history is in the technique used whereby there was a transition from face to face selling messages to the stilted, repetitive, printed advertisements of early newspapers, to the mass communication by radio and television, to the re-personalization of messages via direct mail, cable and internet.

Advertising is at the front of sending the good message to customers and potential customers. According to Taylor (1978), the purpose of advertising is to encourage customers that the company products are the best, improve the image of the company, point out and make a need for products or services, reveal new uses for established products, declare new products and programs, highlight the salespeople's

${ }^{1}$ Corresponding author: h.lashgarian@in.iut.ac.ir 
individual messages, draw customers to the business, and to hold on hand customers.

Today, advertising plays a very important role in competition as below:

- Advertising plays a very important role in customers' life. Customers are the people who buy the product only after they are made aware of the products available in the market. If the product is not advertised, no customer will come to know what products are available and will not buy the product even if the product was for their benefit. Also advertising helps people to obtain the best products because they are able to compare the products and buy. Thus, advertising is important for the customers.

- Advertising plays very important role for the producers and the sellers of the products, because advertising helps increasing sales, identifies their competitors to adjust the level of competition, makes ground for a new product in the market, helps creating goodwill for the company and keeps demand.

- Advertising helps educating people. There are some social issues also which advertising deals with like energy optimization, driving rules, smoking, family planning education, etc.

These days there are more ways than ever before to advertising. Most common of ways is to:

- Generally TV commercial is considered the most effective mass-market advertising type, as is reflected by the high prices TV networks fee for commercial airtime during popular $\mathrm{TV}$ programs. Radio advertising is a type of advertising via the medium of radio and broadcast as radio waves to the air. Airtime is bought from a station or network in switching for airing the commercials. Radio is a growing medium that can be found not only on air, but also online. According to Arbitron, radio has approximately 241.6 million weekly listeners, or more than 93 percent of the U.S. population.

- Billboards are big structures placed in public position which present advertisements to passing passerby. Most often, they are located on main roads with a large amount of passing motor and pedestrian traffic; however, they can be located in any location with large amounts of visitors, such as in stations, in shopping centers or buildings and in stadiums.

- Online advertising is a type of promotion that uses internet for the expressed purpose of delivering marketing messages to draw customers. Examples of online advertising include background advertisements that show on search engine results pages, social network advertising and e-mail marketing.

- Product placement is the purposeful incorporation of commercial content into non-commercial settings, that is, a product plug generated via the fusion of advertising and entertainment. In product placement, the involved audience gets exposed to the brands and products during the natural process of the movie, television program, or content vehicle.

The paper is organized as follows: Section 2 introduces to billboard advertising, Section 3 introduce to network count location problem and modeling of problem, Section 4 explains 
a modified type of imperialist competitive algorithm, a numerical example is given in Section 5 and Section 6 presents the conclusion and future works.

\section{Billboard Advertising}

Taylor et al. (2006) explain billboards as the most common type of outdoor advertising. Over the years billboards have been build in all sorts of shapes and sizes, mostly along highways or major streets in cities in order to attract the attention of people. However there are advantages and disadvantages of using billboards. An obvious benefit is that they are very visible and can be easily observed and so their message is seen by passers. Also, advantages of billboards have been listed as including: potential assignment of the advertisement near the point of sale; 24 -hour attendance; geographic flexibility for local advertisers; visual effect from advertisement size and message creativity. A study of billboard users found that compared with other media, billboards were rated higher in terms of ability to attract new customers, communicate information affordably and to increase sales.

In today's challenging recessionary economy, many companies are forced to shrink their advertising costs to meet the new realities of the marketplace, as are mentioned by Savitz and Shipp (2009).

Murty (2003) illustrates that making decisions on issues with important consequences has become a highly complex problem due to the many competing forces under which the world is operating today, and the manual method very often leads to decisions quite far from being optimal. In fact many bad decisions are being made daily due to this. Many companies have become aware of this problem, and have made efforts to use mathematical models for decision making, and even spent considerable sums of money to acquire software systems to solve these models. However, often the software sits unused because the people who make the decisions are not trained in using it properly. Or, the results obtained by the software may not be practical due to an inappropriate mathematical model being used for the problem. Intelligent modeling is essential to get good results.

Considering the importance of advertising, the purpose of the present paper is to use billboard medium purposefully through a Meta-heuristic algorithm and familiarizing the behavioral science with mathematical issues. Innovative algorithms are the algorithms which are designed for reaching to good answers not necessarily the optimized ones.

\section{Network Count Location Problem}

An origin-destination (OD) matrix is essential for efficient traffic control and management. In the past two decades, we have witnessed the development of a fast growing body of research focused on methods of estimating OD matrices from traffic counts.

Generally, the quality of the estimated OD matrices is greatly dependent upon the accuracy of the input data (traffic counts and prior matrix and so on) and the number and locations of traffic counting points in the network. Conventionally, the impacts of the errors in input data have been investigated through numerical simulation with varying degrees of the accuracy of model input data. There has been, however, very limited attention that has been devoted to the key 
problem of identifying a set of links for which flow information should be collected and used.

Most location models have been developed to determine the optimal locations of facilities so as to serve as much as possible customers, but without particular reference to OD matrix estimation. Hodgson (1990) discussed the flow-capturing location-allocation problem in a transportation network. He assumed that all flows between each OD pair take the same minimum path. Based on Hodgson's earlier work, Berman et al. (1992) presented a model for determining the optimal locations of a number of service facilities so as to intercept the maximum possible potential customer flow. However, studies of this issue in the past seem to ignore the fact that the facilities compete with each other regardless of whether they are of the same or a different chain. The competitive FCLAP is, thus, addressed in the $\mathrm{Wu}$ and Lin (2003) study. They have developed a mathematical model and a greedybased heuristic. Also, Yang et al. (2009) have constructed a bi-level programming static model and designed a heuristic based on a greedy search to solve model. Teodorović and Šelmić (2013) developed a model to determine the locations of the flow-capturing facilities in the transportation network. Berman et al. (1995) further studied the location problem without requirement of the knowledge of flows on all paths. The flow information required in their model is the fraction of customers travelling from a given node to all adjacent nodes (i.e. the turning probabilities at nodes) and the fraction of customers starting their travel from any origin node of the network.

The identification of informative links for a given number of stations in the road network is referred to as the $\mathrm{NCLP}^{2}$. For modeling

${ }^{2}$ Network Count Location Problem of optimal decision making in billboard advertising, we have used network count location problem.

Recent approaches to solve the NCLP follow a number of selection rules. Yang and Zhou (1998) defined the most comprehensive set of rules:

Rule (1) OD covering rule: A certain minimum proportion of trips between each OD pair should be observable.

Rule (2) Maximal flow fraction rule: For a particular OD pair, links with the highest fraction of that OD flow should be selected.

Rule (3) Maximal flow interception rule: The set of links which intercept the maximum number of OD movements should be selected.

Rule (4) Link independence rule: Links with linearly independent flows should be selected.

Yang and Zhou (1998) formulated a rigorous mathematical framework for the problem. The final objective is to find the set of link count locations and the minimum number that minimizes the Maximal Possible Relative Error (MPRE), i.e. a minmaxrisk averse methodology. The developed framework is founded on the above rules. Constraints can be assumed for the upper number of detectors for e.g. budget reasons.

Ehlert et al. (2006) started with the work of Yang and Zhou (1998) and developed a software tool, based on Mixed Integer Programming techniques, which solves the complex problem formulated only mathematically by the previous authors. In 
this software also the extension of Chung's budget constraint and a set of weight, for ranking OD pairs by importance were included.

So far, the sensor problem has been dealt with analytically, i.e. OD flows and vehicle counts have been interrelated in a system of equations. Yang and Zhou (1998) proposed a risk-averse solution in order to minimize the error in traffic count information while maximizing the information inference power. Their solution is strongly dependent on the assignment approach adopted, and, as said in the case of OD-matrix estimation problems, DTA-type of approaches are not yet fully developed. Fei et al. (2007) among other studies adopted a simulation approach to solve the problem. The simulation software used was Dynasmart. Adopting from Yang and Zhou (1998) the 4-rule criterion, they propose to solve the problem with the GLS approach as in and a Kalman filtering method to match real traffic counts and the ones simulated with the DTA.

Now, we explain two cases for modeling of Optimal Decision Making in Billboard Advertising.

1. To maximize number of billboards visits subject to fixed cost for billboard advertising.

According to the NCLP, we have a network that contains some nodes and links. So we assume there is a billboard in each link. Let us define $X=\left(x_{1}, \ldots, x_{a^{\prime}}, \ldots, x_{\text {number of links }}\right)$ as decision variables for network count location problem where $x_{a}=1$ if link $a$ is selected as a informative link, and 0 otherwise. Selection of link $a$ means that billboard $a$ is selected. The maximization problem takes the following form:
$\operatorname{Maximize} F(X)=\sum_{a} v_{a} x_{a}$

subject to $\sum_{a} c_{a} x_{a} \leq C$

$x_{a} \in\{0,1\}$

Where $v_{a}$ is visit number of billboard a, C is a given billboard advertising cost and $c_{a}$ represents costs for placing an advertisement on billboard a.

2. To minimize cost of billboard advertising subject to fixed billboards visits.

The minimization problem takes the following form:

Minimize $G(X)=\sum_{a} c_{a} x_{a}$ subject to $\sum_{a} v_{a} x_{a} \leq V$

$x_{a} \in\{0,1\}$

Where $v_{a}$ is visit number of billboard a, $V$ is a given visit number for advertisement and $c_{a}$ represents costs for placing an advertisement on billboard $a$.

\section{Opposition Based Colonial Competitive Algorithm}

Fogel (1997) explains advantages of evolutionary computation. He illustrates that although the history of evolutionary computation dates back to the 1950 s and 1960 s, only within the last decade have evolutionary algorithms become practicable for solving real-world problems on desktop computers. As computers continue to deliver accelerated performance, these applications will only become more routine. The flexibility of evolutionary algorithms 
to address general optimization problems using virtually any reasonable representation and performance index, with variation operators that can be tailored for the problem at hand, and selection mechanisms tuned for the appropriate level of stringency, gives these techniques an advantage over classic numerical optimization procedures. Moreover, the two-step procedure to self-adapt parameters that control the evolutionary search frees the human operator from having to handcraft solutions, which would often be time consuming or simply infeasible. Evolutionary algorithms offer a set of procedures that may be usefully applied to problems that have resisted solution by common techniques, and can be hybridized with such techniques when such combinations appear beneficial.

Atashpaz-Gargari and Lucas (2007) proposed a new evolutionary algorithm in the Evolutionary Computation field based on the human's socio-political evolution that called Colonial Competitive Algorithm (CCA). Colonial Competitive Algorithm (CCA) and its extended version by opposition-based concept (OCCA) have been briefly reviewed in following subsections.

\subsection{Colonial Competitive Algorithm (CCA)}

This algorithm starts with an initial random population called countries. Some of the best countries in the population selected to be the imperialists and the rest form the colonies of these imperialists. In an $N$ dimensional optimization problem, a country is a $1 \times n$ array. This array is defined as below (Eq. (1)): country $=\left[p_{1}, p_{2}, p_{3}, \ldots, p_{N_{v a r}}\right]$

The algorithm starts with $N$ initial countries and the best of them (countries with minimum cost) chosen as the imperialists. The remaining countries are colonies that each belong to an empire.

The initial colonies belong to imperialists in convenience with their powers. To distribute the colonies among imperialists proportionally, the normalized cost of an imperialist is defined as follow (Eq. (2)):

$C_{n}=\max _{i}\left\{c_{i}\right\}-c_{n}$

Where, $c_{n}$ is the cost of $n$-th imperialist and $C_{n}$ is its normalized cost. Each imperialist that has more cost value, will have less normalized cost value.

Having the normalized cost, the power of each imperialist is calculated as Eq. (3) and based on that the colonies distributed among the imperialist countries.

$p_{n}=\left|\frac{C_{n}}{\sum_{i=1}^{N_{\text {imp }}} C_{i}}\right|$

Fig. 1 shows the initial empires. As shown in this figure, bigger empires have greater number of colonies while weaker ones have less. In this figure imperialist 1 has formed the most powerful empire and consequently has the greatest number of colonies. 


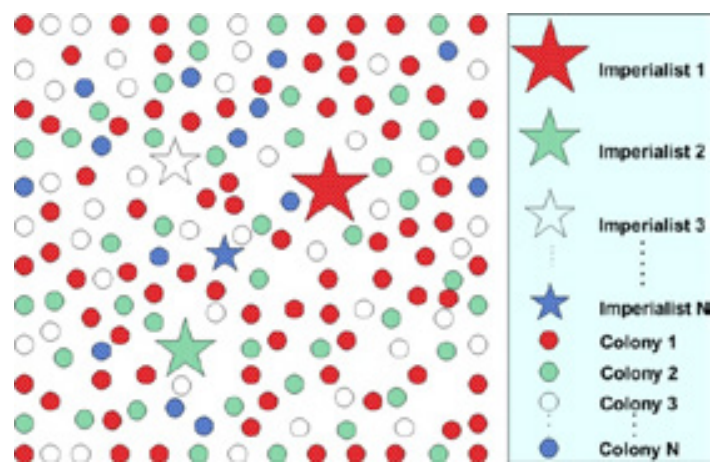

The more colonies an imperialist possess, the bigger is its relevant $\star$ mark.

Fig. 1.

Generating the Initial Empires

To distribute the colonies among imperialist, of the colonies is selected randomly and assigned to their imperialist. The imperialist countries absorb the colonies towards themselves using the absorption policy. The absorption policy shown in Fig. 2 makes the main core of this algorithm and causes the countries move towards to their minimum optima. The imperialists absorb these colonies towards themselves with respect to their power. The total power of each imperialist is determined by the power of its both parts, the empire power plus percents of its average colonies power (Eq. (4)).

T.C. $\cdot_{n}=\operatorname{Cost}\left(\right.$ imperialist $\left._{n}\right)+\xi$ mean $\left\{\operatorname{Cost}\left(\right.\right.$ colonies of empire $\left.\left.{ }_{n}\right)\right\}$

Where T.C. ${ }_{n}$ is total cost of the $n$-th empire and $\xi$ is a positive number which is considered to be less than one.

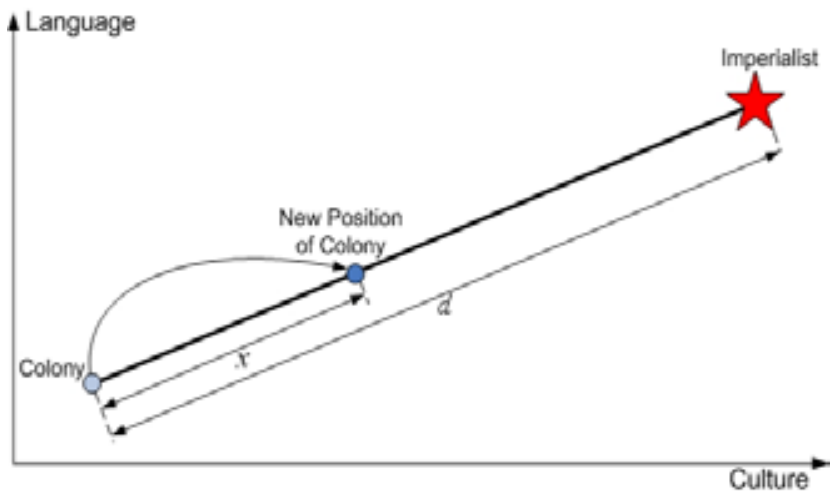

Fig. 2.

Movement of Colonies toward their Relevant Imperialist 
In this algorithm, the imperialistic competition has an important role. During the imperialistic competition, the weak empires will lose their power and their colonies. To model this competition, firstly we calculate the probability of possessing all the colonies by each empire considering the total cost of empire (Eq. (5)).

$$
\text { N.T.C. } \cdot_{n}=\max _{i}\left\{T . C_{\cdot_{i}}\right\}-T . C_{._{n}}
$$

Where T.C. ${ }_{n}$ is the total cost of $n$-th empire and N.T.C. ${ }_{n}$ is the normalized total cost of $n$-th empire. Having the normalized total cost, the possession probability of each empire is calculated as Eq. (6):
$p_{p_{n}}=\left|\frac{N \cdot T \cdot C_{n_{n}}}{\mid \sum_{i=1}^{N_{\text {inp }}} N \cdot T \cdot C_{\cdot_{i}}}\right|$

After a while all the empires except the most powerful one will collapse and all the colonies will be under the control of this unique empire.

Fig. 3 shows a big picture of the modeled imperialistic competition.

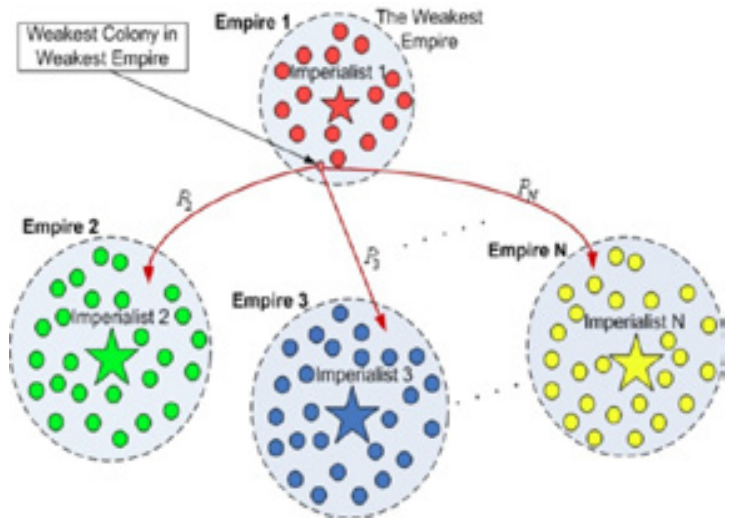

The more powerful an empire is, the more likely it will possess the weakest colony of the weakest empire.

Fig. 3.

Imperialistic Competition

\subsection{Opposition Based Learning (OBL)}

The concept of opposition-based learning (OBL) was introduced by Tizhoosh (2005) and has thus far been applied to accelerate reinforcement learning and back propagation learning in neural networks. The main idea behind $O B L$ is the simultaneous consideration of an estimate and its corresponding opposite estimate (i.e., guess and opposite guess) in order to achieve a better approximation for the current candidate solution.

To clarify, see the Fig. 4 below. 


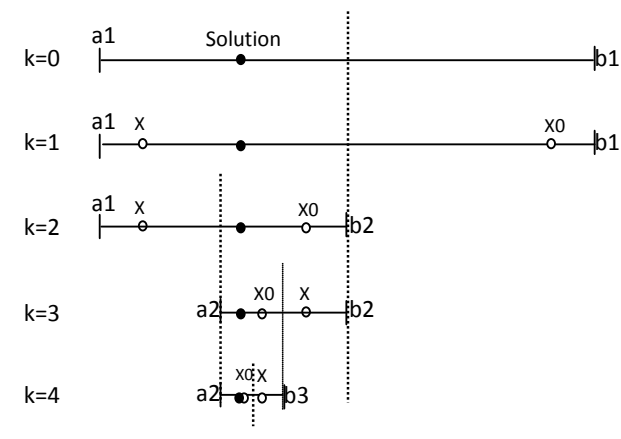

Fig. 4.

Solving a One-Dimensional Equation via Recursive Halving of the Search Interval with Respect to Optimality of the Estimate $x$ and Opposite-Estimate xo

Considering the unite interval $[a 1, b 1]$ in Fig. 4, the solution for a given problem can be found by repeated examination of guess and counter-guess. The opposite number $x o$ of the initial guess $x$ will be generated. Based on which of the estimate or counter-estimate is closer to the solution, the search interval can be recursively halved until either the estimate or the counter-estimate is close enough to an existing solution.

Any population-based optimization algorithm has two main phases, namely, population initialization and evolutionary generating of the new population. Rahnamayan (2007) introduces three possible stages to employ opposition-based optimization to accelerate the parent algorithm.

These three stages are:

1. During population initialization,

2. During population evolution, and

3. After population evolution.

\subsection{Opposition Based Colonial Competitive Algorithm (OCCA)}

Concept of opposition has been employed to accelerate CCA. Opposition concept was utilized to introduce opposition-based population initialization and oppositionbased generation jumping. Azad et al. (2012) have proposed OCCA by embedding these two steps within CCA.

To solve proposed models in the previous section, first, we defined a coverage matrix $\boldsymbol{B}=\left[b_{r a}\right]$ with rows corresponding to paths in $\mathrm{R}$, and columns corresponding to links in $A$, where $b_{r a}=1$ if link a is on path $\mathrm{r}$, and 0 otherwise. With a given prior OD matrix, the coverage matrix can be obtained using a proper assignment model. If path flows between OD pairs are known, link flows $v_{\mathrm{a}}$ can be obtained below:

$v_{a}=\sum_{r} z_{r} b_{r a}=Z B_{a}$

Where $Z=\left(\ldots, z_{r}, \ldots\right)$ is a row vector of all path flows and $B_{a}$ is the a-th column vector of the coverage matrix $\mathbf{B}$.

Let us define $X=\left(x_{1}, \ldots, x_{a}, \ldots, x_{\text {number of links }}\right)$ as decision variables where $x_{a}=1$ if link a is selected as an informative link, and 0 otherwise. By changing mentioned models with $v_{a}$ as we defined, OCCA is ready to solve models. 
Now, we employed opposition based colonial competitive algorithm to determine the desirable number and locations of billboards. In OCCA, countries are defined as below: country $=\left[x_{1}, \ldots, x_{a}, \ldots x_{n u m b e r}\right.$ of billboards $]$

Where $x_{a}=1$ if billboard $a$ is selected, and 0 otherwise. OCCA begins with $N$ initial countries and the best of them (countries with maximum visit for first model and with minimum cost for second model) selected as the imperialists. Empires creation and evolutionary processes continue and OCCA obtain best solution for two models.

\section{Results}

We now employ opposition based colonial competitive algorithm to solve above cases for Sioux Falls city.

Sioux Falls is the largest city in the U.S. state of South Dakota. This network includes 24 centroids and 76 links. There are links input data and prior origin - destination (OD) matrix.

Also, it is assumed that there is a billboard in the each link and Table 1 shows rent cost of each billboard. Network is shown in Fig. 5 .

\section{Table 1}

Rent Cost of Billboards

\begin{tabular}{|c|c|c|c|c|c|}
\hline Billboard Number & Rent Cost & Billboard Number & Rent Cost & Billboard Number & Rent Cost \\
\hline $\mathrm{C} 1$ & $\$ 400$ & $\mathrm{C} 27$ & $\$ 450$ & C52 & $\$ 550$ \\
\hline $\mathrm{C} 2$ & $\$ 850$ & $\mathrm{C} 28$ & $\$ 800$ & C53 & $\$ 800$ \\
\hline $\mathrm{C} 3$ & $\$ 650$ & $\mathrm{C} 29$ & $\$ 650$ & $\mathrm{C} 54$ & $\$ 700$ \\
\hline $\mathrm{C} 4$ & $\$ 850$ & $\mathrm{C} 30$ & $\$ 400$ & C55 & $\$ 550$ \\
\hline $\mathrm{C} 5$ & $\$ 850$ & $\mathrm{C} 31$ & $\$ 600$ & C56 & $\$ 600$ \\
\hline C6 & $\$ 550$ & $\mathrm{C} 32$ & $\$ 400$ & C57 & $\$ 550$ \\
\hline $\mathrm{C} 7$ & $\$ 1,000$ & $\mathrm{C} 33$ & $\$ 500$ & C58 & $\$ 450$ \\
\hline $\mathrm{C} 8$ & $\$ 900$ & $\mathrm{C} 34$ & $\$ 850$ & C59 & $\$ 850$ \\
\hline $\mathrm{C} 9$ & $\$ 800$ & $\mathrm{C} 35$ & $\$ 950$ & C60 & $\$ 1,000$ \\
\hline $\mathrm{C} 10$ & $\$ 750$ & C36 & $\$ 850$ & C61 & $\$ 750$ \\
\hline $\mathrm{C} 11$ & $\$ 500$ & $\mathrm{C} 37$ & $\$ 700$ & C62 & $\$ 450$ \\
\hline $\mathrm{C} 12$ & $\$ 850$ & $\mathrm{C} 38$ & $\$ 800$ & C63 & $\$ 600$ \\
\hline $\mathrm{C} 13$ & $\$ 600$ & C39 & $\$ 700$ & C64 & $\$ 500$ \\
\hline $\mathrm{C} 14$ & $\$ 650$ & $\mathrm{C} 40$ & $\$ 650$ & C65 & $\$ 800$ \\
\hline $\mathrm{C} 15$ & $\$ 950$ & $\mathrm{C} 41$ & $\$ 850$ & C66 & $\$ 650$ \\
\hline $\mathrm{C} 16$ & $\$ 450$ & $\mathrm{C} 42$ & $\$ 650$ & C67 & $\$ 850$ \\
\hline $\mathrm{C} 17$ & $\$ 750$ & $\mathrm{C} 43$ & $\$ 750$ & C68 & $\$ 1,000$ \\
\hline $\mathrm{C} 18$ & $\$ 650$ & $\mathrm{C} 44$ & $\$ 950$ & C69 & $\$ 700$ \\
\hline C19 & $\$ 1,000$ & $\mathrm{C} 45$ & $\$ 800$ & $\mathrm{C} 70$ & $\$ 650$ \\
\hline $\mathrm{C} 20$ & $\$ 850$ & $\mathrm{C} 46$ & $\$ 500$ & C71 & $\$ 400$ \\
\hline $\mathrm{C} 21$ & $\$ 750$ & $\mathrm{C} 47$ & $\$ 400$ & $\mathrm{C} 72$ & $\$ 950$ \\
\hline $\mathrm{C} 22$ & $\$ 800$ & C48 & $\$ 500$ & C73 & $\$ 950$ \\
\hline $\mathrm{C} 23$ & $\$ 800$ & C49 & $\$ 900$ & C74 & $\$ 600$ \\
\hline $\mathrm{C} 24$ & $\$ 1,000$ & C50 & $\$ 400$ & $\mathrm{C} 75$ & $\$ 450$ \\
\hline $\mathrm{C} 25$ & $\$ 500$ & C51 & $\$ 600$ & $\mathrm{C} 76$ & $\$ 450$ \\
\hline $\mathrm{C} 26$ & $\$ 800$ & & & & \\
\hline
\end{tabular}

Total Rent cost of billboard advertising $=52900 \$$ 


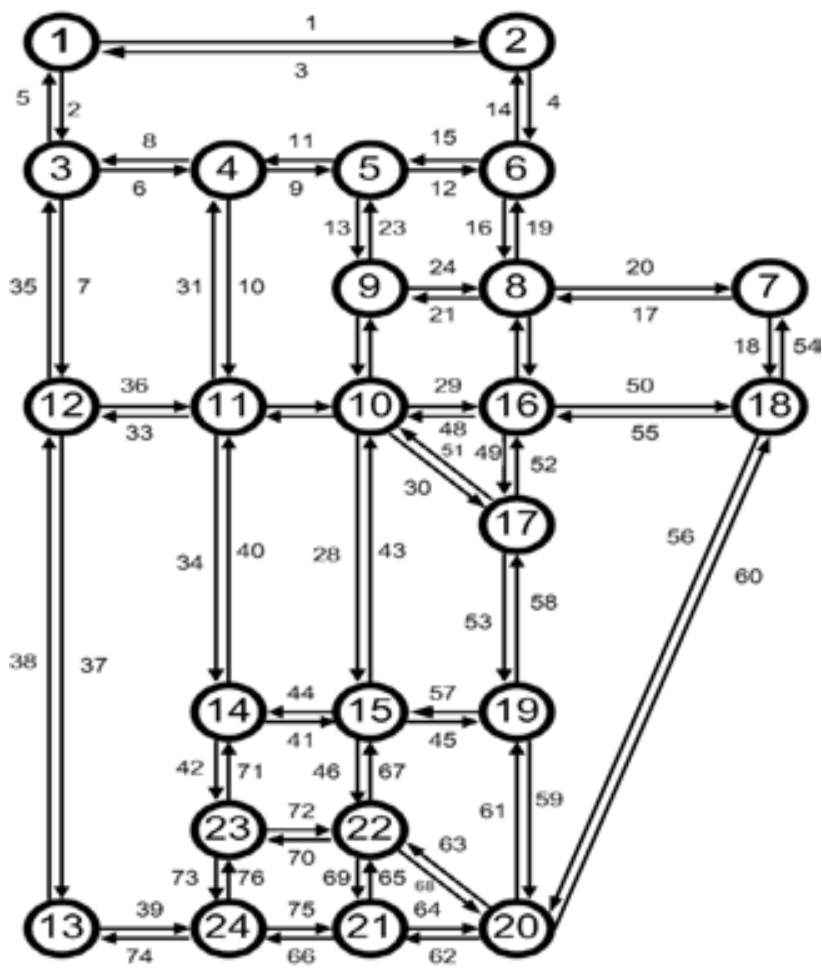

Fig. 5.

Sioux Falls City Network

To solving above models, let us define a coverage matrix $\boldsymbol{B}=\left[b_{r a}\right]$ with rows corresponding to paths in $R$, and columns corresponding to links in $A$, where $b_{r a}=1$ if link $a$ is on path $r$, and 0 otherwise. With a given prior $O D$ matrix, the coverage matrix can be obtained using an appropriate assignment model. If path flows between OD pairs are known, link flows $v_{a}$ can be obtained using Eq. (7): $v_{a}=\sum_{r} z_{r} b_{r a}=Z B_{a}$

Where $Z=\left(\ldots, z_{r}, \ldots\right)$ are to a row vector of all paths flows and $B_{a}$ is the a-th column vector of the coverage matrix $B$.

In research of Azad (2014), NCLP is solved by opposition based colonial competitive algorithm and the main steps in the algorithms that have been modified to solve above cases are summarized and shown in Fig. 6. 


\begin{tabular}{|c|l|l|}
\hline Main Step & Case 1 - maximize number of billboards visits & Case 2 - Minimize cost of billboard advertising \\
\hline Step 1 & $\begin{array}{l}\text { Creation of initial empires: in this step, first, we } \\
\text { have generated initial random countries and initial } \\
\text { opposite countries subject to billboard advertising } \\
\text { cost restriction and then, we have selected fittest } \\
\text { countries. }\end{array}$ & $\begin{array}{l}\text { Creation of initial empires: in this step, first, } \\
\text { we have generated initial random countries and } \\
\text { initial opposite countries subject to billboard } \\
\text { visits restriction and then, we have selected fittest } \\
\text { countries. }\end{array}$ \\
\hline Step 2 & $\begin{array}{l}\text { Evolutionary process according to the objective function. This step includes assimilation, revolution } \\
\text { and imperialistic competition. }\end{array}$ \\
\hline Step 3 & $\begin{array}{l}\text { Creation of new generation: in this step, opposite } \\
\text { colonies generate for produced colonies from } \\
\text { evolutionary process and evaluate by billboard } \\
\text { visits function. }\end{array}$ & $\begin{array}{l}\text { Creation of new generation: in this step, opposite } \\
\text { colonies generate for produced colonies from } \\
\text { evolutionary process and evaluate by billboard } \\
\text { advertising cost function. }\end{array}$ \\
\hline
\end{tabular}

Fig. 6.

Modified Steps of OCCA for Solving Proposed Model

According to the above descriptions, we have solved first model and maximized billboard visits subject to fixed billboard advertising cost. To perform OCCA for first model, billboard advertising cost parameter has varied from $1000 \$$ to $50000 \$$ and results are shown in the Table 2.

\section{Table 2}

Results for Model 1

\begin{tabular}{llll}
\hline $\begin{array}{l}\text { Given Billboard Ads } \\
\text { Cost }(\mathbf{\$})\end{array}$ & $\begin{array}{l}\text { Maximum Percentage of } \\
\text { Visits (\%) }\end{array}$ & $\begin{array}{l}\text { Real Billboard Ads Cost } \\
(\mathbf{\$})\end{array}$ & Number of Billboard \\
\hline 1000 & 10.81 & 1000 & 2 \\
2000 & 20.97 & 2000 & 4 \\
5000 & 31.88 & 4900 & 8 \\
10000 & 53.31 & 9600 & 16 \\
20000 & 73.38 & 19900 & 30 \\
30000 & 87.78 & 29750 & 45 \\
40000 & 95.22 & 39700 & 58 \\
50000 & 99.45 & 49650 & 72 \\
\hline
\end{tabular}

Now, we have solved second model and minimized billboard advertising cost subject to fixed billboard visits. To perform OCCA for second model, billboard visits parameter has varied from $10 \%$ to $99 \%$ and results are shown in the Table 3. 
Table 3

Result for Model 2

\begin{tabular}{llll}
\hline $\begin{array}{l}\text { Given Percentage of } \\
\text { Visits (\%) }\end{array}$ & $\begin{array}{l}\text { Minimum Billboard } \\
\text { Ads Cost (\$) }\end{array}$ & $\begin{array}{l}\text { Real Percentage of } \\
\text { Visits }(\%)\end{array}$ & Number of Billboard \\
\hline 10 & 900 & 9.93 & 2 \\
20 & 2700 & 19.99 & 5 \\
30 & 4150 & 30.03 & 8 \\
40 & 7600 & 39.60 & 11 \\
50 & 10350 & 49.98 & 16 \\
60 & 13400 & 59.52 & 20 \\
70 & 18700 & 69.83 & 27 \\
80 & 23850 & 79.37 & 39 \\
90 & 32650 & 90.26 & 48 \\
99 & 46450 & 97.93 & 68 \\
\hline
\end{tabular}

In this paper, we studied network which include 24 nodes and 76 links. Total number of solutions for models can be calculated as follows:

$\left(\begin{array}{c}76 \\ 1\end{array}\right)+\left(\begin{array}{c}76 \\ 2\end{array}\right)+\ldots+\left(\begin{array}{c}76 \\ 76\end{array}\right)=2^{76}-1=7.5 \times 10^{22}$

In fact, large number of solutions for mentioned problem show the importance of proposed model and coverage of opposition based colonial competitive algorithm imply the validation of results. Now, according to the proposed model, companies can plan with having necessary information.

\section{Conclusion}

To minimize the cost of billboard advertising and maximize the observations of billboards, selecting a suitable billboard location has become one of the most important issues for companies. This paper aims at designing an optimization model for making optimized decision in this case, for a billboard location problem. For this purpose, network count location is employed, which identifies informative links in a network. Afterward, the opposition based colonial competitive algorithm was used to solve optimization model. Finally, an application example, Sioux Falls city network case, is presented to show the applicability and suitability of the proposed model.

Although the proposed model is introduced for using in billboard selection problem, it can also be used with slight modifications in other decision making problems in different field. For further research, we may work on the topic that considers the network with different circumstances or restrictions. Also, we can formulate our model by using multi objective programming and merge two mentioned models. 


\section{References}

Atashpaz-Gargari, E.; Lucas, C. 2007. Imperialist Competitive Algorithm: An algorithm for optimization inspired by imperialistic competition, IEEE Congress on Evolutionary Computation, 4661-4667.

Azad, H.R.L. 2014. An Application of Opposition Based Colonial Competitive Algorithm to Solve Network Count Location Problem, International Journal of Intelligent Systems and Applications. DOI: http://dx.doi.org/10.5815/ ijisa.2014.01.04, 01: 29-35.

Azad, H.R.L.; Boushehri, N.S.; Mollaverdi, N. 2012. Investigating the application of opposition concept to colonial competitive algorithm, International Journal of BioInspired Computation. DOI: http://dx.doi.org/10.1504/ IJBIC.2012.049897, 4(5): 319-329.

Berman, O.; Hodgson, M.J.; Krass, D. 1995. Flowinterception problems, Facility location. In: Z. Drezner (Ed) A survey of applications and methods, New York: Springer-Verlag. 389-426.

Berman, O.; Larson, R.C.; Fouska, N. 1992. Optimal location of discretionary service facilities, Transportation Science, 26(3): 201-211.

Ehlert, A.; Bell, M.G.H.; Grosso, S. 2006. The optimisation of traffic count locations in road networks, Transportation Research Part B: Methodological.DOI: http:// dx.doi.org/10.1016/j.trb.2005.06.001, 40(6): 460-479.

Entrepreneur. 2011. Small Business Encyclopedia: Advertising. Retrieved November 20, 2011.

Fei, X.; Eisenman, S.M.; Mahmassani, H.S. 2007. Sensor coverage and location for real-time prediction in largescale networks. In Proceedings of the 86th TRB Annual meeting, January, Washington D.C.

Fogel, D.B. 1997. The advantages of evolutionary computation. In Proceedings of the Biocomputing and emergent computation, 1-11.
Hodgson, M.J. 1990. A flow-capturing locationallocation model, Geographical Analysis. DOI: http:// dx.doi.org/10.1111/j.1538-4632.1990.tb00210.x, 22(3): 270-279.

Merriam-Webster Dictionary. 2011. Retrieved October 30, 2011.

Murty, K.G. 2003. Optimization Modelsfor Decision Making, Junior Level Web-Book.

O'Barr, W.M. 2010. A Brief History of Advertising in America, Advertising \& Society Review. DOI: http://dx.doi. org/10.1353/asr.0.0046, 11(1).

Rahnamayan, S. 2007. Opposition-based differential evolution. PhD thesis, Department of Systems Design Engineering, University of Waterloo, Waterloo, Ontario, Canada.

Savitz, J.; Shipp, R. 2009. Optimizing Advertising Budgets, Savitz Research Solutions.

Taylor, C.R.; Franke, G.R.; Bang, H. 2006. Use and Effectiveness of Billboards: Perspectives from SelectivePerception Theory and Retail-Gravity Models, Journal of Advertising. DOI: http://dx.doi.org/10.2753/JOA00913367350402, 35(4): 21-34.

Taylor, J.R. 1978. How to start and succeed in a business of your own, Indiana University. 293 p.

Teodorović, D.; Šelmić, M. 2013. Locating flowcapturing facilities in transportation networks: a fuzzy sets theory approach, International Journal for Transport and Traffic Engineering. DOI: http://dx.doi.org/10.7708/ ijtte.2013.3(2).01, 3(2): 103-111.

Tizhoosh, H.R. 2005. Opposition-based learning: a new scheme for machine intelligence. In Proceedings of the International Conference on Computational Intelligence for Modeling, Control and Automation, Vienna, Austria, 695-701.

\section{jitte 159}


Wu, T.H.; Lin, J.N. 2003. Solving the competitive discretionary service facility location problem, European Journal of Operational Research. DOI: http://dx.doi. org/10.1016/S0377-2217(01)00391-5, 144(2):366-378.

Yang, H.; Zhou, J. 1998. Optimal Traffic Counting locations for Origin-destination matrix estimation, Transportation Research Part B: Methodological. DOI: http://dx.doi.org/10.1016/S0191-2615(97)00016-7, 32(2): 109-126.

Yang, J.; Zhang, M.; He, B.; Yang, C. 2009. Bi-level programming model and hybrid genetic algorithm for flow interception problem with customer choice, Computers \& Mathematics with Applications. DOI: http:// dx.doi.org/10.1016/j.camwa.2008.10.035, 57(11-12): 1985-1994. 